\title{
Factors associated with dropout in a lung cancer high-risk cohort - the Liverpool lung project
}

\author{
MICHAEL W. MARCUS ${ }^{1}$, OLAIDE Y. RAJI ${ }^{1}$, YING CHEN ${ }^{1}$, STEPHEN W. DUFFY $^{2}$ and JOHN K. FIELD ${ }^{1}$
}

\author{
${ }^{1}$ Roy Castle Lung Cancer Research Programme, The University of Liverpool Cancer Research Centre, \\ Institute of Translational Medicine, The University of Liverpool, Liverpool L3 9TA; ${ }^{2}$ Wolfson Institute of Preventive Medicine, \\ Barts and The London School of Medicine and Dentistry, Queen Mary University of London, London EC1M 6BQ, UK
}

Received January 23, 2014; Accepted March 4, 2014

DOI: 10.3892/ijo.2014.2371

\begin{abstract}
In long-term longitudinal cohort studies the dropout of participants occurring as a result of withdrawal or lost to follow-up may have greater impact on the effect estimates, if characteristics of participants who drop out and those still active in the study differ significantly. The study aimed to investigate factors associated with dropout in a 5-year follow-up of individuals at 'high-risk' of lung cancer. We studied 'high-risk' group of 1,486 individuals aged 45-79 selected from the Liverpool Lung Prospective (LLP) cohort study using a strategy reflecting only age, smoking duration and history of pulmonary disease. Study subjects were recalled annually from 2005-2009 for follow-up collection of specimens and questionnaire data. The dropout rate over the follow-up time was investigated using the Kaplan-Meier survival curve and the Cox proportional hazard model. Dropout rate was $31 \%$ after an average of 3 annual visits. Female gender hazard ratio (HR) 1.35 (95\% CI 1.09-1.66), current smoking 1.26 (1.02-1.57), prior diagnosis of malignant disease 0.54 (0.36-0.79), home visits 0.67 (0.48-0.94) and systolic blood pressure 1.46 (1.10-1.94) were significantly associated with the dropout rate. Nearly $40 \%$ of individuals selected into the 'high-risk' group by the old criteria were low risk with predicted 5-year absolute risk of less than $2.5 \%$. In conclusion, follow-up of individuals is feasible within the LLP, but may be prone to selective withdrawal attributable to patient's state of health and mobility. We recommend future design of 'high-risk' follow-up studies to consider home visit as a useful strategy to encourage continued participation.
\end{abstract}

\section{Introduction}

Prospective follow-up studies are effective methods of answering research questions on disease aetiological mechanisms and

Correspondence to: Professor John K. Field, Roy Castle Lung Cancer Research Programme, The University of Liverpool Cancer Research Centre, Department of Molecular and Clinical Cancer Medicine, Institute of Translational Medicine, The University of Liverpool, 200 London Road, Liverpool L3 9TA, UK

E-mail: j.k.field@liv.ac.uk

Key words: high-risk cohort, follow-up, lung cancer serve as data sources for estimating incidence and survival rates of diseases within a defined population $(1,2)$. In addition, they provide information on potential influence of changing environmental and life style factors on disease risk through comparison of the same individual at different time points (2). This allows estimation of within-individual variations, which is useful for drawing conclusions on effects of an intervention $(3,4)$. Nevertheless, large scale prospective studies are often difficult to undertake because subjects drop out over time, potentially leading to bias results and erroneous conclusions, particularly if the loss of subjects over time is related to aetiological factors that are associated with the outcomes of interest (5).

Dropout, including withdrawal, loss to follow-up (LTFU) and death can be as high as losing up to two-third of the original samples particularly in studies that require participants to make several rounds of visits for routine follow-up specimen and data collection $(6,7)$. Apart from the duration and number of follow-up, other factors that have been linked to the dropout rate include characteristics of the participants such as age, gender, social status, life style and health condition $(5,7,8)$. Whilst a number of studies has examined dropout in population-based or focused group longitudinal studies (6), to the best of our knowledge no such result has been reported amongst lung cancer high-risk populations. Given that lung cancer is a disease of the aged (increased incidence with ageing), there is a possibility of linkage between dropout and factors related to outcome amongst high-risk individuals. Knowledge of such results may inform strategies for optimal designing, planning and implementation of future lung cancer follow-up studies.

The aim of this study is to investigate factors that are associated with continued participation of selected high-risk individuals in the Liverpool Lung Project (LLP) follow-up during the 2005-2009. In addition, we examined the performance of the criteria previously used to stratify individuals as high-risk in terms of the outcome event, and discuss the potential use of the developed LLP risk model for the selection of individuals into future 'high-risk' follow-up.

\section{Materials and methods}

Study population. The Liverpool Lung Project (LLP) is a population based study conducted in a defined geographical area of Merseyside, which has contiguous electoral wards with a high 
incidence of lung cancer (9). The LLP study design includes a case-control study, 579 newly diagnosed cases of lung cancer and 1,157 age-gender merged population controls were recruited between 1998-2005, a prospective cohort study targeting approximately 7,500 participants recruited between 1998 and 2008, and a follow-up study of high-risk group selected from the prospective cohort population. The prospective cohort subjects consist of people aged 45-79 living within the study area and randomly selected from the population through the Central Operations Group database of patients registered with the General Practices (GPs). A detailed description of patient approached and recruitment have already been described (9).

Selection of high-risk group. The follow-up study started in 2005 and ran through to 2009 utilising predefined set of epidemiological criteria involving age, smoking duration and previous respiratory disease [history of bronchitis, emphysema or pneumonia referred to as 'BEP' (10)] to identify 1,486 high-risk group that were alive, lung cancer free and active participants of the prospective cohort population. In addition to these self-reported risk factors, clinical measures of health status such as systolic and diastolic blood pressure for coronary disease, and lung function test (spirometric) for chronic obstructive pulmonary disease (COPD) were also measured at each annual visit. Individuals were considered 'high-risk' if they were $\geq 65$ years with $>40$ years smoking duration history; $<65$ years with $>20$ years of smoking and a history of BEP; current smokers with $>30$ years smoking history or ex-smokers who had quit within 5 years and with $>40$ years of smoking history. Although, this selection criterion reflects the best available model prior to emergence of lung cancer risk prediction model, it only includes few of the currently identified risk factors and predictors of lung cancer risk $(11,12)$.

The annual follow-up of selected 'high-risk' individuals started in 2005 when all high-risk participants were recalled for follow-up collection of serial specimen samples (blood, sputum and bronchus swab) and further data on their epidemiological, life style and disease diagnosis history. The follow-up strategies include regular appointments, telephone calls to the participants, reminder letters and regular ascertainment of the event outcome (development of lung cancer) and vital status (dead or alive and well). Home visits were also offered to subjects that were unable to attend the clinic due to poor health taking into consideration the ageing nature of the study subjects. All individuals in the cohort were followed up through the Office of National Statistics (ONS) National Health Service (NHS) information service to obtain up to date information on their vital status, including date and cause of death and documentation of multiple cause of death as recorded on the death certificates. In addition, the LLP participant's database was linked with the North West Cancer Intelligence Services (NWCIS) to acquire information on the disease outcome recording cases of lung cancer occurrence, date and details of diagnosis, morphology subtype and treatment history. Comprehensive comorbidity conditions of all individuals in the study were obtained from the Health Episode Statistics (HES) database.

Statistical analysis. Statistical analyses were conducted using dropout as the primary dependent variable. A dropout was defined as anyone who was not observed at a particular visit (year) and was not seen or did not respond to subsequent annual recalls. This includes all cases of LTFU and withdrawal through refusal to continue participation. Separate and joint analyses were undertaken for patient's withdrawal and LTFU. A discrete survival analysis was conducted to adjust the estimated rate for censoring and individual's time to dropout $(13,14)$. This analysis considers the length of follow-up before dropout and treats deaths as censored observations. In addition, individuals that remained active in the follow-up at the time of the analysis were considered as right censored observations; this implies that for these subjects the event of interest (withdrawal or LTFU) did not occur while still being followed up, but we do not know whether or not it will occur at some point in the future. The Kaplan-Meier survival, which is a non-parametric estimation of survival probability over time, was utilised for univariate exploration of the relationship between the dropout and patient's characteristics. The log-rank test was used to compare the Kaplan-Meier curves across levels of each covariate. The Cox proportional hazard model was used to examine the relationship between the dropout rates overtime and all explanatory factors simultaneously.

In order to evaluate the strategy used for selecting individuals into the 'high-risk' group, a retrospective prediction of the 5-year absolute risk of developing lung cancer was undertaken for each participant using the LLP risk model (9-11). The absolute risk calculation was based on the baseline data collected at the time of recruitment into the cohort. Data analyses were performed using Stata software version 12.1 (StataCorp, College Station, TX). All statistical tests were two-tailed carried out at $5 \%$ level of significance.

\section{Results}

Table I shows the pattern of follow-up outcome by annual recall visit. More than half of subjects on annual follow-up $(62 \%)$ are still active in the study. The average follow-up visit attendance was 3 (range 1-5 visit attendants) as at the end of the study in 2009. A total of 460 subjects $(31 \%)$ have dropped out of the study due to LTFU $(n=160 ; 11 \%)$ and withdrawal $(n=300,20 \%)$. The proportion of dropout rate and death was higher earlier during the initial stage of the follow-up but reduced over time.

Table II shows distribution of the baseline characteristics by end-of-study follow-up outcome. Subject's age, gender, smoking status or smoking duration, prior diagnosis of malignant disease and systolic blood pressure were independently and statistically significantly associated with overall followup outcome. The dropout rate was slightly higher for female (33.1\%) compared to male $(28.3 \%)$, current smokers $(33.2 \%)$ relative to ex-smokers $(27.5 \%)$, and in individuals with no previous diagnosis of malignant disease $(32.2 \%)$ compared with individuals with previous diagnosis of malignant disease $(22.8 \%)$. Dropout rate for those with previous history of pneumonia (31.4\%) was very close to those without history of pneumonia (30.9\%). The average age of subjects dropping out was statistically significantly higher than the overall average age for all participants or the active subjects in the follow-up. Fig. 1 shows the Kaplan-Meier curves and log-rank test for covariates with independent statistically significant relation- 
Table I. Participation status of the subjects at each annual follow-up recall.

\begin{tabular}{|c|c|c|c|c|c|c|c|c|}
\hline \multirow{3}{*}{$\begin{array}{l}\text { Follow-up status } \\
\text { Lost to follow-up }\end{array}$} & \multicolumn{7}{|c|}{ Annual follow-up visit } & \multirow{3}{*}{$\frac{\text { Total }}{160(10.8)}$} \\
\hline & 1 & \multicolumn{2}{|c|}{2} & \multicolumn{2}{|c|}{3} & \multicolumn{2}{|c|}{4} & \\
\hline & $75 \quad(5.1)$ & 54 & $(4.5)$ & 25 & $(2.4)$ & 6 & (0.6) & \\
\hline Withdrawal & $155(10.4)$ & 105 & $(8.7)$ & 29 & $(2.8)$ & 11 & $(1.2)$ & $300(20.2)$ \\
\hline Deceased & $52 \quad(3.5)^{\mathrm{a}}$ & 22 & (1.8) & 19 & (1.9) & 9 & (0.9) & $102 \quad(6.9)$ \\
\hline Active & $1,204(81.0)$ & 1,023 & $(85.0)$ & 950 & (92.9) & 924 & (97.3) & $924(62.1)$ \\
\hline Cumulative dropouts $^{\mathrm{a}}$ & $230(15.5)$ & 389 & $(26.2)$ & 443 & (29.9) & 460 & $(31.0)$ & \\
\hline
\end{tabular}

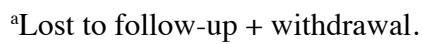

Table II. Distribution of subject's baseline characteristics by overall (end of study) follow-up outcome.

\begin{tabular}{|c|c|c|c|c|c|}
\hline \multirow[b]{2}{*}{ Characteristics } & \multicolumn{3}{|c|}{ FU outcome status } & \multirow[b]{2}{*}{ All subjects } & \multirow[b]{2}{*}{ P-value } \\
\hline & Dropout & Active & Deceased & & \\
\hline \multicolumn{6}{|l|}{ Age (years) } \\
\hline$<50$ & 28 & $82(71.9)$ & $4 \quad(3.5)$ & $114 \quad(7.7)$ & \\
\hline $50-59$ & 161 & $349(65.7)$ & $21 \quad(4.0)$ & $531(35.7)$ & $<0.01$ \\
\hline $60-69$ & $179(29.4)$ & $380(62.5)$ & $49 \quad(8.1)$ & $608(40.9)$ & \\
\hline$\geq 70$ & $92(39.5)$ & $113(48.5)$ & $28(12.0)$ & $233(15.7)$ & \\
\hline Mean \pm SD & $62.2 \pm 7.7$ & $60.5 \pm 7.5$ & $64.8 \pm 7.4$ & $61.3 \pm 7.7$ & \\
\hline \multicolumn{6}{|l|}{ Gender } \\
\hline Male & $188(28.3)$ & $415(62.5)$ & $61 \quad(9.2)$ & $664(44.7)$ & 0.002 \\
\hline Female & $272(33.1)$ & $509(61.9)$ & $41 \quad(5.0)$ & $822(55.3)$ & \\
\hline \multicolumn{6}{|l|}{ Smoking status } \\
\hline Current smokers & $301(33.2)$ & $554(61.1)$ & $52 \quad(5.7)$ & $907(61.0)$ & 0.014 \\
\hline Ex-smokers & $159(27.5)$ & $370(63.9)$ & $50 \quad(8.6)$ & $579(39.0)$ & \\
\hline \multicolumn{6}{|l|}{ Smoking duration (years) } \\
\hline$<40$ & $125(26.7)$ & $318(68.0)$ & $25 \quad(5.3)$ & $468(31.5)$ & 0.021 \\
\hline $40-60$ & $312(32.5)$ & $575(59.9)$ & (7.6) & $960(64.7)$ & \\
\hline$\geq 60$ & $23(40.4)$ & $30(52.6)$ & $4 \quad(7.0)$ & $57 \quad(3.8)$ & \\
\hline \multicolumn{6}{|l|}{ Pneumonia diagnosis } \\
\hline Yes & $86(31.4)$ & $170(62.0)$ & (6.6) & $274(18.4)$ & 0.97 \\
\hline No & $374(30.9)$ & $754(62.2)$ & $84 \quad(6.9)$ & $1,212(81.6)$ & \\
\hline \multicolumn{6}{|l|}{ Malignant disease } \\
\hline Yes & $43(22.8)$ & $122(64.6)$ & $24(12.7)$ & $189(12.7)$ & $<0.01$ \\
\hline No & $417 \quad(32.2)$ & $802(61.8)$ & $78 \quad(6.0)$ & $1,297(87.3)$ & \\
\hline \multicolumn{6}{|l|}{ Family history } \\
\hline No history & $181(33.9)$ & $310(58.1)$ & $(8.1)$ & $534(35.9)$ & 0.11 \\
\hline Early onset & 151 (30.6) & $310(62.9)$ & $(6.5)$ & $493(33.2)$ & \\
\hline Late onset & $128(27.9)$ & $304(66.2)$ & $27 \quad(5.9)$ & $459(30.9)$ & \\
\hline \multicolumn{6}{|l|}{ Systolic BP (mmHg) } \\
\hline Normal $(<120)$ & $101(27.3)$ & $246(66.5)$ & $(6.2)$ & $370(25.1)$ & \\
\hline Pre-hypertension (120-139) & $154(28.1)$ & $359(65.5)$ & $(6.4)$ & $548(37.2)$ & 0.02 \\
\hline $\operatorname{High} \mathrm{BP}(\geq 140)$ & $198(35.6)$ & $319(57.3)$ & $40 \quad(7.2)$ & $557(37.8)$ & \\
\hline \multicolumn{6}{|l|}{ Diastolic BP (mmHg) } \\
\hline Normal $(<80)$ & $202(30.1)$ & $416(62.0)$ & (7.9) & $671(45.5)$ & \\
\hline Pre-hypertension (80-89) & $133(30.5)$ & $277(63.5)$ & $(6.0)$ & $436(29.6)$ & 0.48 \\
\hline High BP $(\geq 90)$ & $118(32.1)$ & $231(62.8)$ & $19 \quad(5.2)$ & $368(25.0)$ & \\
\hline
\end{tabular}


Table III. Hazard ratio from multivariable Cox proportional model for predictors of subject's participation in annual follow-up.

\begin{tabular}{|c|c|c|c|c|c|c|c|c|c|}
\hline \multirow[b]{2}{*}{ Characteristics } & \multicolumn{3}{|c|}{ Withdrawn } & \multicolumn{3}{|c|}{ Lost to follow-up } & \multicolumn{3}{|c|}{ Dropout (withdrawn + LTFU) } \\
\hline & \multicolumn{2}{|c|}{$\mathrm{HR}(95 \% \mathrm{CI})$} & \multirow[t]{2}{*}{ P-value } & \multicolumn{2}{|c|}{$\mathrm{HR}(95 \% \mathrm{CI})$} & \multirow[t]{2}{*}{ P-value } & \multicolumn{2}{|c|}{$\mathrm{HR}(95 \% \mathrm{CI})$} & \multirow[t]{2}{*}{ P-value } \\
\hline Current status & & & & & & & & & \\
\hline Deceased & 1.45 & $(0.76-2.75)$ & 0.26 & 0.33 & $(0.05-2.40)$ & 0.27 & 1.10 & $(0.60-2.03)$ & 0.75 \\
\hline \multicolumn{10}{|l|}{ Age } \\
\hline$<50$ & & 1.00 & \multirow{4}{*}{0.02} & & 1.00 & \multirow{4}{*}{0.75} & & 1.00 & \multirow{4}{*}{0.10} \\
\hline $50-59$ & 2.01 & $(1.03-3.93)$ & & 1.02 & $(0.58-1.80)$ & & 1.38 & $(0.90-2.11)$ & \\
\hline $60-69$ & 2.00 & $(0.99-4.05)$ & & 0.89 & $(0.46-1.72)$ & & 1.34 & $(0.85-2.12)$ & \\
\hline$\geq 70$ & 3.35 & $(1.48-7.58)$ & & 0.64 & $(0.23-1.77)$ & & 1.92 & $(1.07-3.45)$ & \\
\hline \multicolumn{10}{|l|}{ Gender } \\
\hline Female & 1.61 & $(1.24-2.09)$ & 0.002 & 1.00 & $(0.71-1.41)$ & 0.99 & 1.35 & $(1.09-1.66)$ & 0.005 \\
\hline \multicolumn{10}{|l|}{ Smoking status } \\
\hline Ex-smokers & & 1.00 & & & 1.00 & & & 1.00 & \\
\hline Current smoker & 1.21 & $(0.92-1.59)$ & 0.16 & 1.37 & $(0.93-2.02)$ & 0.11 & 1.26 & $(1.02-1.57)$ & 0.04 \\
\hline \multicolumn{10}{|l|}{ Smoking duration } \\
\hline$<40$ & & 1.00 & \multirow{3}{*}{0.43} & & 1.00 & \multirow{3}{*}{0.50} & & 1.00 & \multirow{3}{*}{0.47} \\
\hline $40-60$ & 1.06 & $(0.73-1.55)$ & & 0.76 & $(0.48-1.22)$ & & 0.96 & $(0.72-1.29)$ & \\
\hline$\geq 60$ & 0.75 & $(0.37-1.51)$ & & 0.64 & $(0.21-1.92)$ & & 0.72 & $(0.40-1.29)$ & \\
\hline \multicolumn{10}{|l|}{ Pneumonia } \\
\hline Yes & 0.82 & $(0.57-1.17)$ & 0.27 & 1.00 & $(0.64-1.57)$ & 0.99 & 0.91 & $(0.69-1.21)$ & 0.43 \\
\hline \multicolumn{10}{|l|}{ Malignant disease } \\
\hline Yes & 0.46 & $(0.28-0.76)$ & 0.002 & 0.71 & $(0.38-1.32)$ & 0.28 & 0.54 & $(0.36-0.79)$ & 0.002 \\
\hline \multicolumn{10}{|l|}{ Family history } \\
\hline No history & & 1.00 & & & 1.00 & \multirow{3}{*}{0.26} & & 1.00 & \multirow{3}{*}{0.06} \\
\hline Early onset ( $<60$ years) & 0.70 & $(0.50-0.99)$ & & 0.91 & $(0.59-1.40)$ & & 0.78 & $(0.60-1.02)$ & \\
\hline Late onset ( $\geq 60$ years) & 0.77 & $(0.58-1.03)$ & 0.08 & 0.72 & $(0.47-1.08)$ & & 0.76 & $(0.60-0.97)$ & \\
\hline \multicolumn{10}{|l|}{ Home visit } \\
\hline Yes & 0.54 & $(0.35-0.84)$ & 0.005 & 1.04 & $(0.60-1.79)$ & 0.90 & 0.67 & $(0.48-0.94)$ & 0.02 \\
\hline \multicolumn{10}{|c|}{ Diastolic blood pressure $(\mathrm{mmHg})$} \\
\hline Pre-hypertension (120-139) & 0.78 & $(0.58-1.06)$ & 0.27 & 1.33 & $(0.89-1.98)$ & 0.37 & 0.95 & $(0.75-1.20)$ & 0.87 \\
\hline $\operatorname{High} \mathrm{BP}(\geq 140)$ & 0.87 & $(0.63-1.21)$ & & 1.11 & $(0.68-1.79)$ & & 0.94 & $(0.71-1.23)$ & \\
\hline Systolic blood pressure $(\mathrm{mmH}$ & & & & & & & & & \\
\hline Pre-hypertension (120-139) & 1.20 & $(0.86-1.67)$ & 0.006 & 0.88 & $(0.57-1.38)$ & 0.64 & 1.08 & $(0.83-1.41)$ & 0.01 \\
\hline $\operatorname{High} \mathrm{BP}(\geq 140)$ & 1.70 & $(1.19-2.43)$ & & 1.06 & $(0.65-1.72)$ & & 1.46 & $(1.10-1.94)$ & \\
\hline Predicted LLP risk (\%) & 1.04 & $(0.99-1.10)$ & 0.08 & 1.03 & $(0.96-1.10)$ & 0.43 & 1.03 & $(0.99-1.08)$ & 0.10 \\
\hline
\end{tabular}

ships with dropout. Independent significant association with dropout was observed for subject's age $\mathrm{P}=0.001$, smoking duration $\mathrm{P}=0.006$, systolic blood pressure $\mathrm{P}=0.03$ and prior diagnosis of malignant disease $\mathrm{P}=0.01$. There were high probabilities of dropout over time for older subjects, smokers with long duration of smoking history and those with prior diagnosis of malignant disease.

Table III presents the results of the association between dropout during the follow-up period and all the patient's characteristics. Elderly (aged $\geq 70)$, hazard ratio (HR) $1.92(95 \% \mathrm{CI}$ 1.07-3.45), female gender 1.35 (1.09-1.66), current smoking $1.26(1.02-1.57)$, prior diagnosis of malignant disease 0.54 (0.36-0.79), home visits 0.67 (0.48-0.94) and systolic blood pressure 1.46 (1.10-1.94) were significantly associated with dropout rate in the multivariable model. The separate analysis of the two dropout outcomes, withdrawn and LTFU, showed a different pattern of associations with patient's covariates. There was a statistically significant increase in subject's withdrawal hazard rate with age; elderly participants aged $\geq 70$ years were approximately three times more likely to withdraw from the follow-up compared to those aged $<50$ years. The hazards of withdrawal were also higher for female compared to male and current smokers against ex-smokers, but no significant association was seen with smoking duration. Participants with prior diagnosis of malignant disease had low follow-up withdrawal hazards. The withdrawal hazard was lower 0.54 (0.35-0.84) for those on home visits compared to those not on home visit list and participants who were hypertensive (high systolic BP) 
A

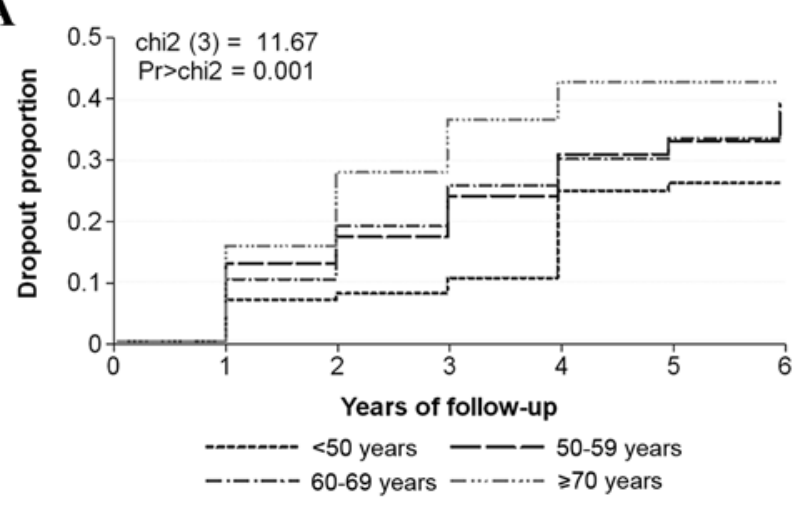

C

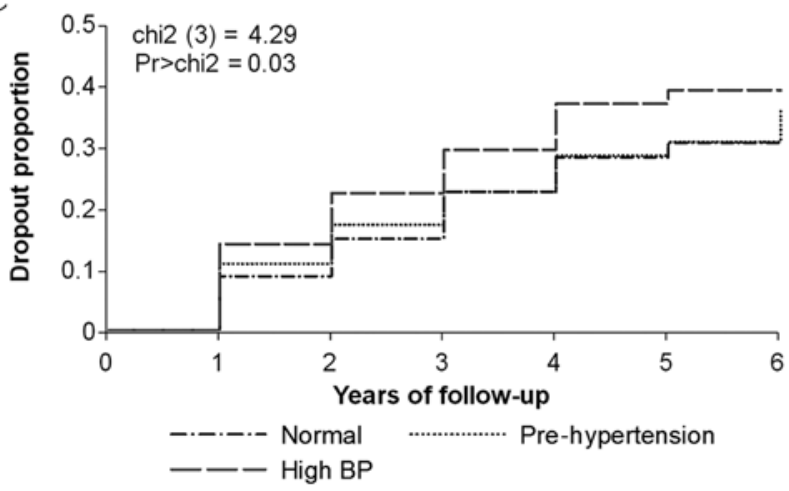

B

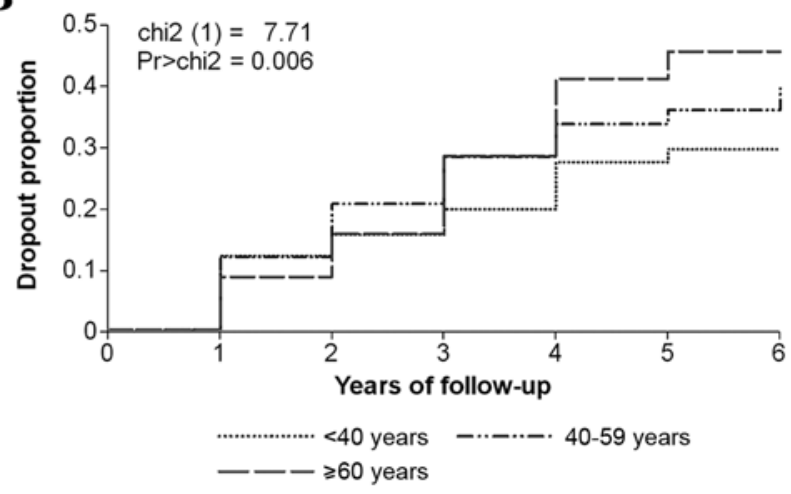

D

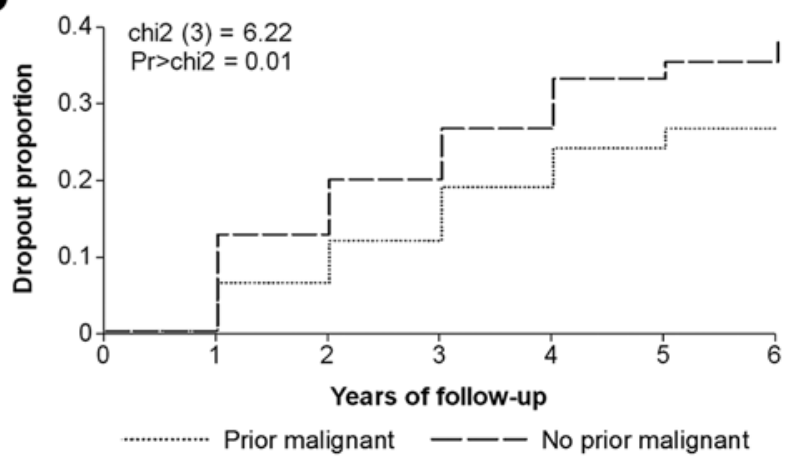

Figure 1. Kapler-Meier curves for the dropout during annual follow-up by epidemiological factors. (A) Age; trend test for equality of survivor functions. (B) Smoking duration; trend test for equality of survivor functions. (C) Systolic blood pressure; trend test for equality of survivor functions. (D) Prior diagnosis of malignant disease; log-rank test for equality of survivor functions.

Table IV. Distribution of predicted 5-year risk of lung cancer by disease status.

\begin{tabular}{lccr}
\hline & \multicolumn{2}{c}{ Subject's cohort status } & All subjects \\
\cline { 2 - 4 } & $\begin{array}{c}\text { Malignancy } \\
(\mathrm{n}=46,3.1 \%)\end{array}$ & $\begin{array}{c}\text { Disease-free } \\
(\mathrm{n}=1,439,96.9 \%)\end{array}$ \\
\hline$<1$ & $0(0.0)$ & $267(100.0)$ & $267(18.0)$ \\
$1.0-2.49$ & $2(0.8)$ & $246(99.2)$ & $248(16.7)$ \\
$2.5-4.90$ & $12(3.0)$ & $390(97.0)$ & $402(27.1)$ \\
$5.0-9.90$ & $22(5.5)$ & $376(94.5)$ & $398(26.8)$ \\
$\geq 10$ & $10(5.9)$ & $160(94.1)$ & $170(11.5)$ \\
Summary measures & & & $5.05 \pm 4.98$ \\
Mean \pm SD & $8.72 \pm 6.12$ & $4.93 \pm 4.91$ & 3.81 \\
Median & 6.65 & 3.7 & 0.13 \\
Minimum & 1.47 & 51.13 & 51.32 \\
Maximum & 31.57 & & \\
\hline
\end{tabular}

were more likely to withdraw from the study compared to normal subjects HR 1.70 (1.19-2.43). However, none of the patient characteristics were associated with LTFU and none of the dropout outcomes was significantly associated with predicted lung cancer risk, although the median predicted risk was slightly higher among the dropouts
(5.30 \pm 5.09 ; median, 4.16) compared to those that remain active (4.72 \pm 4.81 ; median, 3.43$)$.

Table IV shows the distribution of retrospective 5-year absolute risk predicted by the LLP risk model. The majority of participants (61.8\%) selected as 'high-risk' had 5-year absolute risk below the threshold of $5.0 \%$ currently used in an on-going 
primary care implementation programme (PCIP) early detection study and in the United Kingdom Lung Screening (UKLS) trial. There was an increase in the proportion of lung cancer cases with predicted risk; participants with 5-year risk above $10 \%$ had the highest proportion of lung cancer occurrence $(6 \%)$ and no lung cancer was identified during the follow-up period among individuals with very low predicted 5-year absolute risk that were selected as part of the 'high-risk' group.

\section{Discussion}

This study examined risk factors that are associated with dropout of individuals at high-risk of developing lung cancer in the Liverpool Lung Project (LLP) 'high-risk' follow-up study. Female gender, current smoking, prior diagnosis of malignant disease, home visitation and systolic blood pressure were significantly associated with dropout rate.

The high number of deaths in the first year of follow-up as reported in Table $I$ is due to the fact that follow-up period in this group included all follow-up from the first recruitment of the study participants in 1996. The overall attrition (dropout) rate in the LLP 'high-risk' follow-up of $31 \%$ (withdrawal, 20\%; LTFU, $11 \%$ ) was considerably modest and similar to rates reported in other longitudinal studies involving regular recalls of patients, which ranges between 14 and 33\% (5,7,15). This percentage decreases to $24 \%$ after correction for deceaced subjects. The LTFU were typically subjects who have moved out of the area and were therefore untraceable. The lack of significant predictors for LTFU is a suggestion of non-selective participation in terms of participants that were LTFU, and an indication that LTFU in this study is a random process. This provides reassurance that potential effects of systematic bias on risk effects may not be present.

Among the patient characteristics examined, the gender, smoking status, home visits and systolic blood pressure, were statistically associated with dropout whereas subject's age, gender, malignant disease, home visits and systolic blood pressure were significantly associated with withdrawal. None of the aforementioned patient characteristics were associated with LTFU. Apart from the gender effect on withdrawal rate, all other factors identified as determinants of dropout indicate that withdrawal in the LLP 'high-risk' follow-up study may be linked to ill health and lack of mobility. Poor health condition is a major factor often reported to influence participation in follow-up studies $(4,5,7)$. In this study, a substantial number of participants refused to continue participation because they could not provide the required specimen or were too old to travel to attend the LLP clinics. In addition, our results suggest that females were more likely to drop out of the follow-up than their male counterparts. This observation is consistent with the result from other studies (6).

The comprehensive investigation of attrition as reported herein is very important not only for gauging follow-up intervals, but also for designing strategies to maximise compliance and encouraging continued participation in future studies. Interventions may include setting up criteria to exclude at onset people with potential for health deterioration during the follow-up. However, projecting future health conditions at baseline would be difficult. The exclusion of individuals may also lead to non-representation of the follow-up study with respect to the general population distribution of the event under investigation. Instead, an oversampling of those individuals at the initial phases of the follow-up could be undertaken to ensure that sufficient numbers remain at the end of the follow-up period to ensure that the result is generalizable to the population it aims to depict. One important constraint for oversampling of a particular group of subjects is cost-effectiveness of such approach; one would need to assess the relative cost of such an approach to its effectiveness. Another useful strategy to encourage continued participation would be to provide special assistance to individuals according to their needs and preferences, such as making home visit provision for individuals who are unable to attend either due to ill health or old age; this however would inevitably be a more expensive follow-up method. In the LLP follow-up study, withdrawal rate was about $54 \%$ lower among those on home visit; this may be an indication of the effectiveness and value for money for the approach.

The strengths of this study include the population-based design, the large sample size, the long follow-up period and the use of ONS and the HES data minimises the chances of missing information. In addition, detailed information concerning the potential risk factors in the LLP was collected using standardised questionnaires. However, the result of this study must be considered in the light of a number of limitations. First, we have examined dropout in relation to only a number of possible baseline characteristics that may be influential determinants of either withdrawal or LTFU. We do not know if dropout was related to other factors that are latent (unmeasured) in our analysis.

Secondly, the design of the 'high-risk' follow-up study estimated that the size of the planned cohort would enable the selection of about 1,500 individuals from which $60-70 \%$ (90-105) lung cancer cases would be expected to occur in 10 years of follow-up (10). However, the total number of lung cancer cases that occurred in this 'high-risk' follow-up cohort with a 3 years average follow-up period was only 47 (3.2\%). This number of lung cancer occurrence may be a reflection of selection of individuals with risk not sufficiently high enough even though this reflects the best available lung cancer model as at the time of selection, inclusion of low risk individuals will mean long follow-up time before occurrence of the event outcome.

The retrospective prediction of absolute risk of lung cancer for the 'high-risk' using the LLP risk model showed that only $38 \%$ of selected individuals would qualify to be in the follow-up using the 5\% risk threshold currently in use in our early detection primary care implementation programme and UKLS. This finding suggests a need for the modification of the 'high-risk' group in terms of making changes to selection criteria in order to achieve its specific outcome events.

In conclusion, a modest dropout rate was recorded in the LLP 'high-risk cohort' after an average of 3 years of follow-up indicating feasibility of annual follow-up in this cohort of subjects. Efforts to encourage continued participation should be implemented. Given the aging nature of the cohort, arranging home visits by the research nurse to elderly participants unable to attend clinics may prove useful in reducing the study's withdrawal rate but may lead to extra cost. Finally, the use of the LLP risk model will ensure that individuals at 
sufficiently high-risk of the disease are the ones selected for follow-up, thereby maximising the benefit-harm ratio of the study.

\section{Acknowledgements}

This study was supported by grants from the Roy Castle Lung Cancer Foundation, the European Community's Seventh Framework Programme (FP7/2007-2013) under grant agreement no. HEALTH-F2-2010-258677 (CURELUNG project) and grant agreement no. 258868 (LCAOS project).

\section{References}

1. Vandenbroucke JP: Observational research, randomised trials, and two views of medical science. PLoS Med 5: e67, 2008.

2. Rothman KJ, Greenland S: Cohort studies. In: Rothman KJ, Greenland S and Lash TL: Modern Epidemiology. 3rd edition. Lippincott Williams \& Wilkins, Philadelphia, PA, pp100-110, 2008.

3. Pirie PL, Thomson SJ, Mann SL, et al: Tracking and attrition in longitudinal school-based smoking prevention research. Prev Med 18: 249-256, 1989.

4. Guey LT, Bromet EJ, Gluzman SF, Zakhozha V and Paniotto V: Determinants of participation in a longitudinal two-stage study of the health consequences of the Chornobyl nuclear power plant accident. BMC Med Res Methodol 8: 27, 2008.

5. Oleske DM, Kwasny MM, Lavender SA and Andersson GB Participation in occupational health longitudinal studies: predictors of missed visits and dropouts. Ann Epidemiol 17: 9-18, 2007.
6. Van Beijsterveldt CE, van Boxtel MP, Bosma H, Houx PJ, Buntinx $F$ and Jolles J: Predictors of attrition in a longitudinal cognitive aging study: the Maastricht Aging Study (MAAS). J Clin Epidemiol 55: 216-223, 2002.

7. Chatfield MD, Brayne CE and Matthews FE: A systematic literature review of attrition between waves in longitudinal studies in the elderly shows a consistent pattern of dropout between differing studies. J Clin Epidemiol 58: 13-19, 2005.

8. Phillips KA, Butow PN, Stewart AE, et al: Predictors of participation in clinical and psychosocial follow-up of the kConFab breast cancer family cohort. Fam Cancer 4: 105-113, 2005.

9. Field JK, Smith DL, Duffy S and Cassidy A: The Liverpool Lung Project research protocol. Int J Oncol 27: 1633-1645, 2005.

10. Cassidy A, Myles JP, Liloglou T, Duffy SW and Field JK: Defining high-risk individuals in a population-based molecularepidemiological study of lung cancer. Int J Oncol 28: 1295-1301, 2006.

11. Cassidy A, Myles JP, van Tongeren M, Page RD, Liloglou T, Duffy SW and Field JK: The LLP risk model: an individual risk prediction model for lung cancer. Br J Cancer 98: 270-276, 2008.

12. Spitz MR, Hong WK, Amos CI, et al: A risk model for prediction of lung cancer. J Natl Cancer Inst 99: 715-726, 2007.

13. Singer JD and Willett JB: It's about time: Using Discrete-Time Survival Analysis to study duration and the timing of events. J Educ Stat 18: 155-195, 1993.

14. Willett JB and Singer JD: Investigating onset, cessation, relapse, and recovery: why you should, and how you can, use discrete-time survival analysis to examine event occurrence. J Consult Clin Psychol 61: 952-965, 1993.

15. Bildt C, Alfredsson L, Punnett L, Theobald H, Torgen $M$ and Wikman A: Effects of drop out in a longitudinal study of musculoskeletal disorders. Occup Environ Med 58: 194-199, 2001. 